\title{
Influência da restrição alimentar e do estresse térmico sobre parâmetros fisiológicos em ovinos
}

[Influence of food restriction and heat stress on physiological parameters in sheep]

\author{
J. Halfen ${ }^{1}$, N.M. Rahal ${ }^{1}$, A.A. Barbosa ${ }^{2}$, M.N. Corrêa ${ }^{2}$, F.A.B. Del Pino ${ }^{2}$,
} V.R. Rabassa², C.C. Brauner ${ }^{2}$, E. Schmitt ${ }^{2 *}$

${ }^{1}$ Aluno de pós-graduação - Universidade Federal de Pelotas - UFPel - Pelotas, RS

${ }^{2}$ Universidade Federal de Pelotas - UFPel - Pelotas, RS

\section{RESUMO}

Objetivou-se avaliar as alterações fisiológicas de ovinos submetidos à restrição alimentar, expostos à radiação solar e à sombra. Dez borregas mestiças foram divididas igualmente em dois grupos: grupo radiação solar - GRS, animais expostos ao sol durante o dia; e grupo sombra - GS, animais alocados dentro de um galpão à sombra. Nos seis dias iniciais de experimento, os animais foram submetidos à restrição alimentar, com acesso apenas à água, já expostos ao sol ou à sombra. Nos seis dias subsequentes, foi ofertada dieta composta por ração e feno de alfafa (3\%PV). Os parâmetros avaliados foram frequência respiratória (FR), temperatura retal (TR), $\beta$-hidroxibutirato $(\mathrm{BHB}), \mathrm{pH}$ urinário, ingestão de matéria seca (IMS) e dados bioclimáticos (temperatura, umidade relativa do ar e índice de temperatura e umidade ITU). A FR foi o parâmetro em que houve maior diferença significativa entre os grupos $(\mathrm{p}<0,05)$. O balanço energético negativo foi constatado em todos os animais (BHB $>0,8 \mathrm{mmol} / \mathrm{L} ; \mathrm{pH}<7,0)$. Ovelhas que sofrem restrição alimentar durante períodos de alta temperatura e umidade têm menor frequência respiratória e temperatura interna, independentemente de estar na sombra ou pleno sol. Porém, quando normalizado a oferta de alimento as ovelhas em pleno sol têm menor ingestão de matéria seca.

Palavras-chave: ingestão de matéria seca, $\beta$-hidroxibutirato, temperatura retal

\begin{abstract}
We aimed to evaluate physiological changes in sheep submitted to food restriction, exposed to the sun or shade. Ten ewe lambs were equally divided into two groups: Sun Radiation Group - GRS, exposed to sun during day hours, and Shade Group - GS, with animals placed inside a barn. In the first six days of experiment, animals were submitted to food restriction, with access to fresh water, already exposed to sun and shade. In the following six days alfalfa hay and concentrate were provided to the animals $(3 \% B W)$. Parameters assessed were respiratory rate (FR), rectal temperature (TR), $\beta$-hydroxybutyrate, urinary $p H$, dry matter intake (IMS) and climate data (air temperature, humidity, and temperature-humidity indexITU). The parameter that most differed between groups was FR. All animals presented negative energy balance $(B H B>0.8 m m o l / L ; p H<7,0)$. Ewe lambs submitted to food restriction during periods of high temperature and humidity have lower respiratory rate and intern temperature, independently of being exposed to sun or shade. However, when food was offered animals exposed to sun had lower dry matter intake.
\end{abstract}

Keywords: dry matter intake, $\beta$-hydroxybutyrate, rectal temperature

\section{INTRODUÇÃO}

A ovinocultura brasileira tem potencial para ser uma importante atividade pecuária no Brasil. Sua produção se estende pelo território nacional, sendo fonte de renda e subsistência em diversos estados, todavia os principais desafios enfrentados pelos produtores estão relacionados

Recebido em 28 de janeiro de 2020

Aceito em 28 de abril de 2020

*Autor para correspondência (corresponding author)

E-mail:schmitt.edu@gmail.com 
ao ambiente, em que a restrição alimentar e o estresse térmico aparecem como fatores de grande impacto, principalmente devido às peculiaridades das duas regiões mais produtoras do território nacional (Viana, 2008; Silva et al., 2010).

A região Nordeste e o Rio Grande do Sul representam mais de $80 \%$ de população ovina do país. Apesar das características raciais diferirem nas duas regiões, a restrição de alimento causada pelas secas ou pelas geadas, respectivamente, é um grande entrave nas eficiência desses sistemas, tendo o Nordeste o agravante da falta de conforto térmico exercido pelas altas temperaturas em determinadas épocas do ano (Neff et al., 2018; Viana, 2008; Aquino et al., 2016). Desse modo, produtores rurais são comumente desafiados a lidar com fatores múltiplos de estresse que podem acometer os animais, levando estes a um quadro, muitas vezes, de balanço energético negativo com reflexos significativos na lucratividade da produção animal (Sejian et al., 2012).

As mudanças climáticas dos últimos anos têm intensificado as pesquisas com o bem-estar animal como objeto de estudo, a fim de minimizar as perdas econômicas decorrentes dos efeitos do clima sobre a produção animal nos trópicos (Souza e Batista, 2012) e atender a uma demanda do mercado consumidor. Mercado esse que se tornou cada vez mais exigente na compra do produto levando em conta não somente a qualidade, mas também o bem-estar dos animais (Neff et al., 2018).

A determinação deste fator dentro do sistema produtivo pode ser verificada com base em avaliações dos parâmetros fisiológicos e bioquímicos como frequência cardíaca, frequência respiratória e análises séricas ou comportamentais (Casella et al., 2016; Ricci et al., 2017). Ao longo dos anos, os efeitos do estresse térmico devido a mudanças sazonais estão se tornando mais severos e frequentes (Habibu et al., 2018). Nesse contexto, diversos estudos têm demonstrado que um ambiente estressante pode gerar problemas respiratórios, hormonais, falta de apetite, aumento da incidência de doenças e, ainda diminuição da produção de carne (Sousa Júnior et al., 2008; Freitas et al., 2017; Furtado et al., 2020).

Assim, estresse térmico e restrição alimentar são intercorrências rotineiras na realidade da ovinocultura, porém a avaliação das repercussões metabólicas e fisiológicas nesses animais ainda vem sendo pouco estudada. Portanto, em consideração aos fatores previamente citados, a hipótese aqui levantada é a de que animais submetidos a estresses ambientais e nutricionais sofrem alterações metabólicas que podem vir a afetar o desempenho produtivo. O objetivo do presente estudo foi avaliar as alterações fisiológicas de ovinos submetidos à restrição alimentar expostos à radiação solar e à sombra.

\section{MATERIAL E MÉTODOS}

Todos os procedimentos experimentais foram aprovados pelo Comitê de Ética de Experimentação Animal (Ceea) da Universidade Federal de Pelotas ( $n^{\circ}$ 4649). O experimento foi realizado nas proximidades do galpão de ovinos do Núcleo de Pesquisa, Ensino e Extensão em Pecuária - Nupeec, na Universidade Federal de Pelotas (3148'24'S, 52²4'39'O), durante 15 dias, entre os meses de fevereiro e março de 2016. Foram utilizadas 10 borregas contemporâneas, mestiças das raças Texel e Corriedale, com 14 meses de idade, divididas aleatoriamente em dois grupos experimentais: grupo sombra $(\mathrm{GS} ; \mathrm{n}=5)$ e grupo radiação solar (GRS; $n=5)$. Ambos os grupos foram submetidos a um período de restrição alimentar, a fim de se avaliarem os efeitos conjuntos dos estresses ambiental e nutricional.

Após um período de três dias de adaptação às condições de manejo do experimento iniciou-se o período de restrição alimentar, no qual, durante o dia, os animais de ambos os grupos permaneciam contidos com cabresto. Posterior aos seis dias de restrição alimentar (dias -6, -5, -4, -3, -2 e -1), iniciou-se o período de fornecimento da dieta (dias 0 a 5), quando os animais receberam ração comercial peletizada e feno de alfafa, em uma proporção concentrado:volumoso de 45:55\%. O fornecimento da dieta era dividido em dois tratos ao longo do dia (às 9h e às 16h30), sob uma oferta de $3 \%$ do PV e sobra estimada para $5 \%$, em comedouros individuais para controle de ingestão de matéria seca.

Amostras da dieta ofertada aos animais foram enviadas para laboratório (3r Lab, Belo Horizonte, Minas Gerais, Brasil) e continham aproximadamente $18,8 \%$ /MS de $\mathrm{PB}, 37,62 \% / \mathrm{MS}$ de FDN, 24,27\%/MS de FDA e 1,29Mcal/kg MS 
de ELI. Além disso, os animais tiveram acesso à água ad libitum durante todo o período experimental.

Para determinação do status metabólico dos animais, foram avaliados os níveis de betahidroxibutirato (BHB) e do $\mathrm{pH}$ urinário. Para determinação do BHB sérico, coletou-se $5 \mathrm{~mL}$ de sangue por punção da veia jugular utilizando-se acoplador e agulha $25 \times 7 \mathrm{~mm}$ para coleta a vácuo em tubo com ativador de coágulo após o início do período de restrição alimentar, nos momentos (horas) 24, 36, 48, 54, 66, 78, 90, 102, 114, 156, e, após o início da oferta de alimento, às 24 e 48 horas. As amostras foram centrifugadas (Centrífuga Sirius 4000, Sieger, Brasil) a $1.800 \mathrm{x}$ g por 15 minutos, em temperatura ambiente, para obtenção do soro sanguíneo, sendo este avaliado em analisador bioquímico automático Labmax Plenno (Labtest Diagnóstica SA, Brasil).

$\mathrm{O} \mathrm{pH}$ urinário foi avaliado com medidor de $\mathrm{pH}$ de bancada (mPA-210, MS Tecnopon, Piracicaba, São Paulo, Brasil) a partir do início da restrição alimentar, nos momentos (horas) 24, 36, 48, 54, $60,66,72,78,84,90,96,102,108,114,120,156$, e, após o início de oferta de alimento, às $24 \mathrm{~h}, 48 \mathrm{~h}$ e 72h. Também foram avaliados os parâmetros de frequência respiratória (FR) e temperatura retal (TR), quatro vezes ao dia, durante todo o período experimental, às $9 \mathrm{~h}, 11 \mathrm{~h}, 13 \mathrm{~h}$ e $16 \mathrm{~h} 30$. A FR foi determinada por meio de avaliação visual, observando-se os movimentos do flanco durante 60 segundos, para se obterem resultados expressos em movimentos por minuto ( $\mathrm{mpm}$ ), e a TR, mediante o uso de termômetro clínico digital (G-Tech TH150, Accumed-Glicomed, Brasil).

Os dados bioclimáticos (temperatura ambiente, em ${ }^{\circ} \mathrm{C}$, e umidade relativa do ar) foram obtidos por termo-higrômetros digitais (Modelo 7429, TFA Dostmann, Alemanha) portáteis, localizados nos ambientes onde os animais permaneciam durante o dia, e dados também eram obtidos diariamente da estação meteorológica da Embrapa Capão do Leão-RS. Por meio desses dados, determinou-se o índice de temperatura e umidade (ITU), utilizando-se a fórmula ITU $=$ TA $-\{(0,55$ - 0,55 UR) (TA - 58) $\}$, em que TA corresponde à temperatura ambiente $\left({ }^{\circ} \mathrm{F}\right)$ e UR, à umidade relativa do ar (\%) (Agriculture..., 1990).
A análise estatística foi realizada utilizando-se a ferramenta PROC MIXED do programa estatístico $\mathrm{SAS}^{\circledR}$ University Edition, 9.4. No modelo empregado, o tratamento (GS ou GRS) e o período (restrição ou alimentado) representavam os efeitos fixos sob a variável resposta e a interação entre efeitos fixos (efeito do grupo dentro de cada período). A normalidade dos dados foi previamente avaliada dentro de cada grupo, utilizando-se o comando PROC UNIVARIATE. Para a comparação entre médias utilizou-se o teste de Tukey. Todos os testes foram rodados com um nível de significância de 5\%.

\section{RESULTADOS E DISCUSSÃO}

Os valores médios de frequência respiratória encontrados estiveram acima do limite fisiológico descrito por Navarre e Pugh (2002), sendo a maior média para esse parâmetro constatada no GRS, $220 \mathrm{mpm}$, no dia 2 (nono dia de experimento), inferindo-se que esses animais passaram por um estresse térmico severo (Silanikove, 2000). Com exceção do dia -2, o GRS apresentou FR média significativamente maior quando comparado ao GS $(\mathrm{P}<0,05)$ (Fig.1). Especula-se que tal resultado pode ter ocorrido devido a algum fator climático não mensurado neste estudo, como radiação e/ou velocidade do vento, amenizando a sensação térmica dos ambientes, principalmente do GRS, e não impactandonos valores de FR, assim como descreve Barbosa e Silva (1995), que cita que radiação e velocidade do evento podem ser fatores que contribuem para o conforto térmico em ovinos.

O incremento da frequência respiratória pode ser considerado o principal mecanismo de controle da homeotermia sob as condições ambientais impostas, acompanhado pela taxa de sudação (Marai et al., 2007). Devido à movimentação dos animais para se alimentar,a própria atividade da ingesta de alimentos e a produção de calor decorrente da metabolização do alimento, a partir do dia 0 notou-se também diferença significativa na FR entre os períodos com e sem restrição alimentar $(\mathrm{P}<0,05)$ dentro de cada um dos grupos (GS: 56mpm, com restrição, e $77 \mathrm{mpm}$, sem restrição; e GRS: 103mpm, com restrição, e 143, sem restrição). 


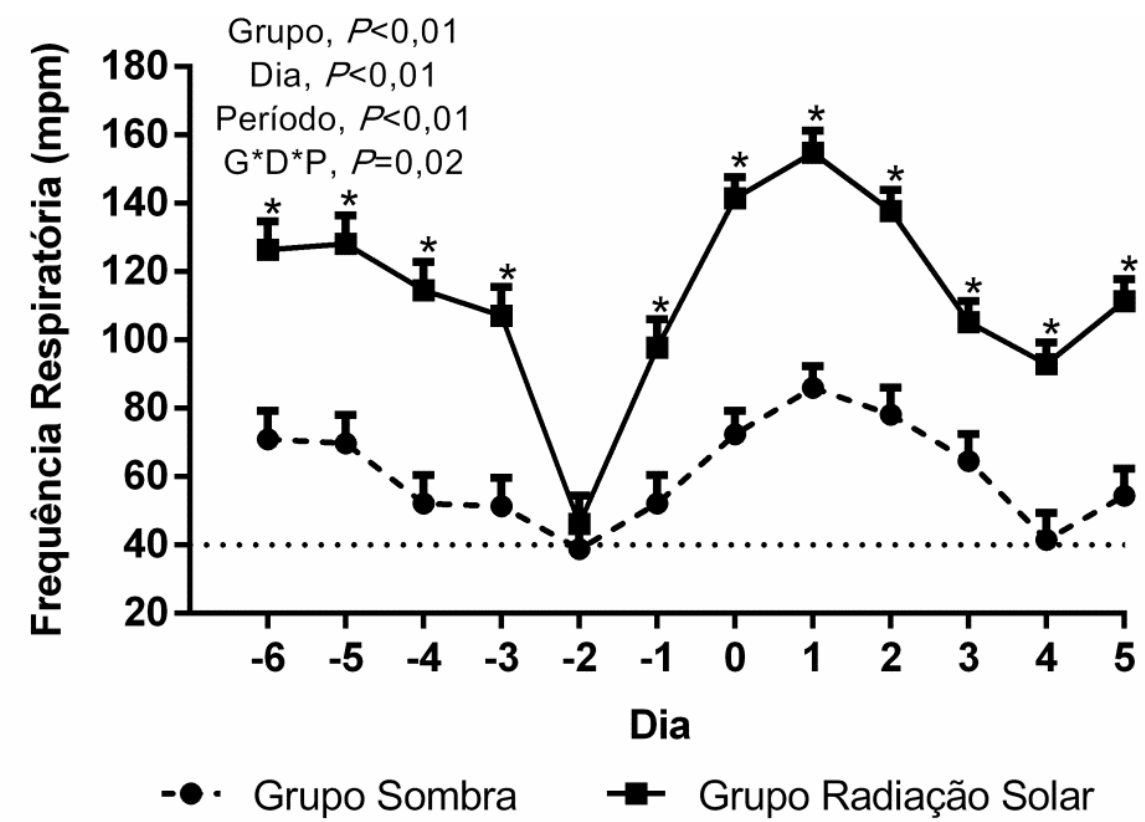

Figura 1. Frequência respiratória média (movimentos por minuto) de ovinos sob período de restrição alimentar (dias -6;-5;-4;-3;-2;-1) ou não (dias $0 ; 1 ; 2 ; 3 ; 4 ; 5)$, expostos à radiação solar ou à sombra, no município de Capão do Leão, Rio Grande do Sul, Brasil. Período: restrição ou alimentado. Linha pontilhada indica limite superior de referência para o parâmetro dessa espécie (Navarre e Pugh, 2002). *Diferença significativa $(\mathrm{P}<0,05)$ entre os grupos pelo teste de comparação de médias de Tukey.

As médias de temperatura retal dos animais do GS permaneceram abaixo do limite superior dos parâmetros fisiológicos durante todo o período avaliado, enquanto o GRS ultrapassou $40^{\circ} \mathrm{C}$ de TR nos dias 2 e 3, diferenciando-se significativamente do GS nestes e nos dois dias subsequentes (Fig. 2). Geralmente, ovinos são capazes de manter sua homeotermia também pela dissipação do excesso de calor corpóreo e, em animais lanados, como os utilizados neste estudo, esse mecanismo ocorre principalmente através de orelhas e membros (Silva e Starling, 2003). Entretanto esse processo só será eficiente caso a temperatura ambiente e a sensação térmica não sejam menores que a temperatura do animal.

Caso a dissipação do calor seja ineficiente ocorre o aumento da temperatura retal, conforme se observou no dia 2, quando um dos animais do GS apresentou TR de $41,2^{\circ} \mathrm{C}$ (a maior encontrada neste estudo) e a média deste parâmetro para animais do GRS foi mais alta que o limite superior fisiológico. Aliado a isso, neste dia, o ITU máximo observado foi de 86 (Tab.1), classificado como severo (Agriculture..., 1990).
Assim como para o parâmetro FR, a TR também foi significativamente maior no período sem restrição alimentar $(\mathrm{P}<0,05)$, possivelmente em razão da maior atividade dos animais devido à ingestão de alimentos e ao incremento calórico gerado por estes (Marai et al., 2007).

Em ovinos submetidos à combinação de dois fatores estressantes (restrição alimentar e condições que induziram ao estresse térmico), foi possível constatar que animais submetidos concomitantemente a esses desafios podem sofrer alterações fisiológicas severas, reduzindo significativamente valores de hematócrito, hemoglobina, glicose, entre outros. Porém, ao se avaliar cortisol, os níveis mais altos foram encontrados nos animais submetidos ao estresse térmico isoladamente, apontando que o estresse nutricional, quando avaliado individualmente, pode impactar com menor gravidade nas alterações fisiológicas dos indivíduos avaliados (Sejian et al., 2010). 


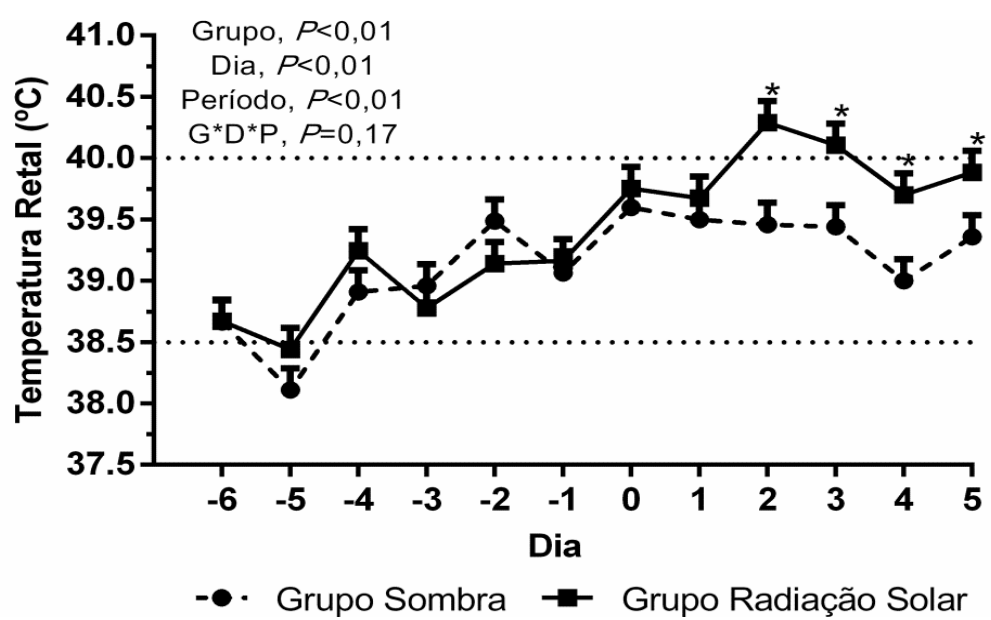

Figura 2. Temperatura retal média $\left({ }^{\circ} \mathrm{C}\right)$ de ovinos sob período de restrição alimentar (dias -6;-5;-4;-3;-2;1) ou não (dias $0 ; 1 ; 2 ; 3 ; 4 ; 5)$, expostos à radiação solar ou à sombra, no município de Capão do Leão, Rio Grande do Sul, Brasil. Linhas pontilhadas indicam limites inferior e superior de referência para o parâmetro dessa espécie (Feitosa, 2014).Período: restrição ou alimentado. *Diferença significativa $(\mathrm{P}<0,05)$ entre os grupos pelo teste de Tukey.

Tabela 1. Valores médios de temperatura, umidade e índice de temperatura e umidade (ITU) a que ovinos foram expostos durante o período experimental, sendo estes radiação solar e sombra durante os dias 18 a 29 de fevereiro de 2016, no município de Capão do Leão, Rio Grande do Sul, Brasil

\begin{tabular}{|c|c|c|c|c|c|c|c|c|c|c|c|c|}
\hline \multirow{3}{*}{ Dia } & \multicolumn{6}{|c|}{ Manhã } & \multicolumn{6}{|c|}{ Tarde } \\
\hline & \multicolumn{3}{|c|}{ Grupo sombra } & \multicolumn{3}{|c|}{ Grupo radiação solar } & \multicolumn{3}{|c|}{ Grupo sombra } & \multicolumn{3}{|c|}{ Grupo radiação solar } \\
\hline & $\begin{array}{c}\mathrm{T} \\
\left({ }^{\circ} \mathrm{C}\right)\end{array}$ & $\begin{array}{c}\text { Umidade } \\
(\%)\end{array}$ & ITU & $\begin{array}{c}\mathrm{T} \\
\left({ }^{\circ} \mathrm{C}\right)\end{array}$ & $\begin{array}{c}\text { Umidade } \\
(\%)\end{array}$ & ITU & $\begin{array}{c}\mathrm{T} \\
\left({ }^{\circ} \mathrm{C}\right)\end{array}$ & $\begin{array}{c}\text { Umidade } \\
(\%)\end{array}$ & ITU & $\begin{array}{c}\mathrm{T} \\
\left({ }^{\circ} \mathrm{C}\right)\end{array}$ & $\begin{array}{c}\text { Umidade } \\
(\%)\end{array}$ & ITU \\
\hline-6 & 27,2 & 78,5 & 78,2 & 27,4 & 74,5 & 78,0 & 36,3 & 75 & 91,9 & 32,6 & 59,5 & 83,5 \\
\hline-5 & 24 & 81,5 & 73,5 & 27,3 & 73 & 77,7 & 28,2 & 67 & 78,3 & 31,5 & 62,5 & 82,4 \\
\hline-4 & 25 & 79,5 & 74,9 & 26 & 74 & 75,9 & 26,9 & 71,5 & 77 & 30,5 & 59,5 & 80,5 \\
\hline-3 & 24,4 & 77,5 & 73,7 & 26 & 74 & 75,9 & 27,6 & 71,5 & 77,1 & 25,6 & 69,5 & 74,7 \\
\hline-2 & 26,8 & 71 & 75,6 & 30,6 & 85,5 & 84,8 & $\dagger$ & $\dagger$ & $\dagger$ & $\dagger$ & $\dagger$ & $\dagger$ \\
\hline-1 & $\dagger$ & $\dagger$ & $\dagger$ & $\dagger$ & $\dagger$ & $\dagger$ & 28,3 & 73,5 & 79,3 & 34,2 & 63 & 86,3 \\
\hline 0 & 27,2 & 73 & 77,5 & 34,7 & 58,5 & 86,1 & 32,6 & 56 & 82,8 & 38,8 & 35 & 86,2 \\
\hline 1 & 28,8 & 74 & 80,1 & 32,8 & 64,5 & 84,7 & 30,2 & 71 & 81,9 & 35,3 & 55 & 86,2 \\
\hline 2 & 29,4 & 80,5 & 82 & 33,3 & 65,5 & 85,6 & 27,7 & 68 & 77,7 & 33,7 & 65 & 86 \\
\hline 3 & $\dagger$ & $\dagger$ & $\dagger$ & $\dagger$ & $\dagger$ & $\dagger$ & 24,1 & 72 & 72,8 & 30,7 & 49,5 & 79,1 \\
\hline 4 & 21,5 & 65,5 & 68,3 & 26,6 & 60 & 75,1 & 26,5 & 44 & 73,1 & 34,4 & 23,5 & 78,8 \\
\hline 5 & 23,8 & 48 & 70 & 38 & 54,5 & 89,9 & 28,9 & 35 & 74,8 & 35,3 & 32 & 81,5 \\
\hline
\end{tabular}

T: Temperatura.

ITU: Índice de temperatura e umidade.

†Dados ausentes.

Não houve diferença entre os valores médios de BHB sérico dos grupos ao longo do período avaliado (Fig. 5). Níveis séricos de BHB entre 0,8 e $1,6 \mathrm{mmol} / \mathrm{L}$ indicam inadequada ingestão de energia, correspondendo a um quadro de balanço energético negativo e à ativação do metabolismo lipídico (Navarre e Pugh, 2002). Quando o BHB é abundante na corrente sanguínea, o cérebro obtém partes substanciais de sua energia a partir da oxidação deste metabólito, principalmente em períodos prolongados de fome. Nesse caso, o cérebro também pode utilizar o BHB ou até substituir a glicose como combustível primário, suprindo cerca de $60 \%$ de sua necessidade de energia (Laeger et al., 2010). Tal fato pode justificar, assim, o detectado no corrente estudo, em que nenhum animal apresentou debilidade ou apatia após um período de seis dias de restrição alimentar. 
Foi possível observar que, mesmo 48 horas após o início do fornecimento de dieta, os animais permaneciam com valores séricos de BHB acima de $0,8 \mathrm{mmol} / \mathrm{L}$, possivelmente devido à permanência da ativação da via do metabolismo lipídico, associada ainda ao início da ingesta de alimento (Laeger et al., 2010). Em estudo realizado com borregas da raça Corriedale durante as quatros estações do ano, no Rio Grande do Sul (Ribeiro et al., 2003), foi observado que, durante o verão, a glicemia apresentou-se abaixo dos níveis fisiológicos, enquanto o betahidroxibutirato sempre se manteve elevado nesses períodos, o que sugere que os animais estivessem em balanço energético negativo, havendo mobilização das reservas corporais provavelmente ocasionada pela estiagem que ocorreu na época. Todavia, mesmo com a chuva, os animais demoraram a retornar os valores basais desses metabólitos, corroborando o que foi encontrado no presente estudo.

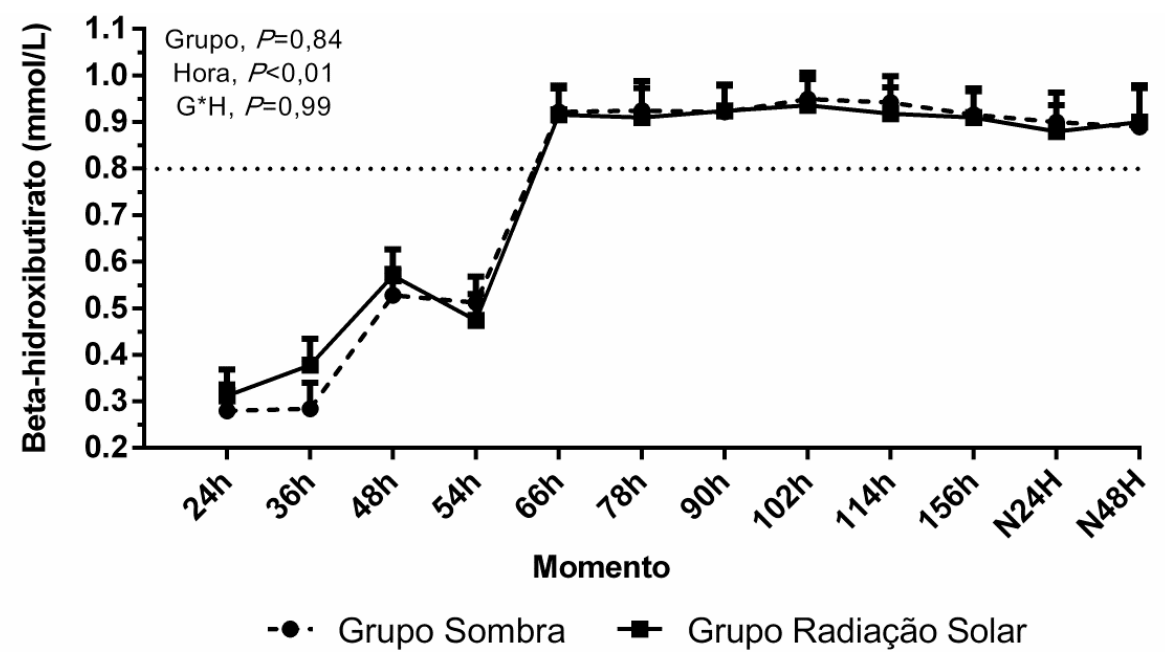

Figura 5. Valores médios de beta-hidroxibutirato (mmol/L) sérico de ovinos sob restrição alimentar (24h até 156h) ou não (N24h; N48h), expostos à radiação solar ou à sombra, no município de Capão do Leão, Rio Grande do Sul, Brasil. Linha pontilhada indica limite inferior para caracterização de balanço energético negativo (Navarre e Pugh, 2002).

N24H: 24h após o início do período de fornecimento da dieta.

N48H: 48h após o início do período de fornecimento da dieta.

Devido ao balanço energético negativo e à ativação do metabolismo lipídico associada ao aumento de cetonas circulantes, o pH urinário pode diminuir (Navarre e Pugh, 2002), conforme notado nos animais deste experimento a partir das 24 horas de restrição alimentar. $\mathrm{O}$ pH urinário de ovinos pode variar principalmente devido ao tipo de alimentação ingerida. Animais a pasto ou submetidos à dieta rica em fibra possuem $\mathrm{pH}$ urinário mais elevado (alcalina) devido à alimentação. Esse parâmetro é caracterizado fisiológico quando está em torno de 7,2 a 8 (Navarre e Pugh, 2002).
Quando ocorrem alterações no $\mathrm{pH}$ urinário, geralmente existem alterações sistêmicas e não apenas um processo localizado no sistema (Taffarel et al., 2012). Ao iniciar-se o período de fornecimento da dieta aos animais, após 24 horas, ainda foi verificado $\mathrm{pH}$ médio de 6,3 para o GS e 6,2 para o GRS, o que sugere ainda eliminação de corpos cetônicos na urina. Já no momento N48H, foi possível observar que os valores de $\mathrm{pH}$ se encontravam dentro dos limites fisiológicos. 


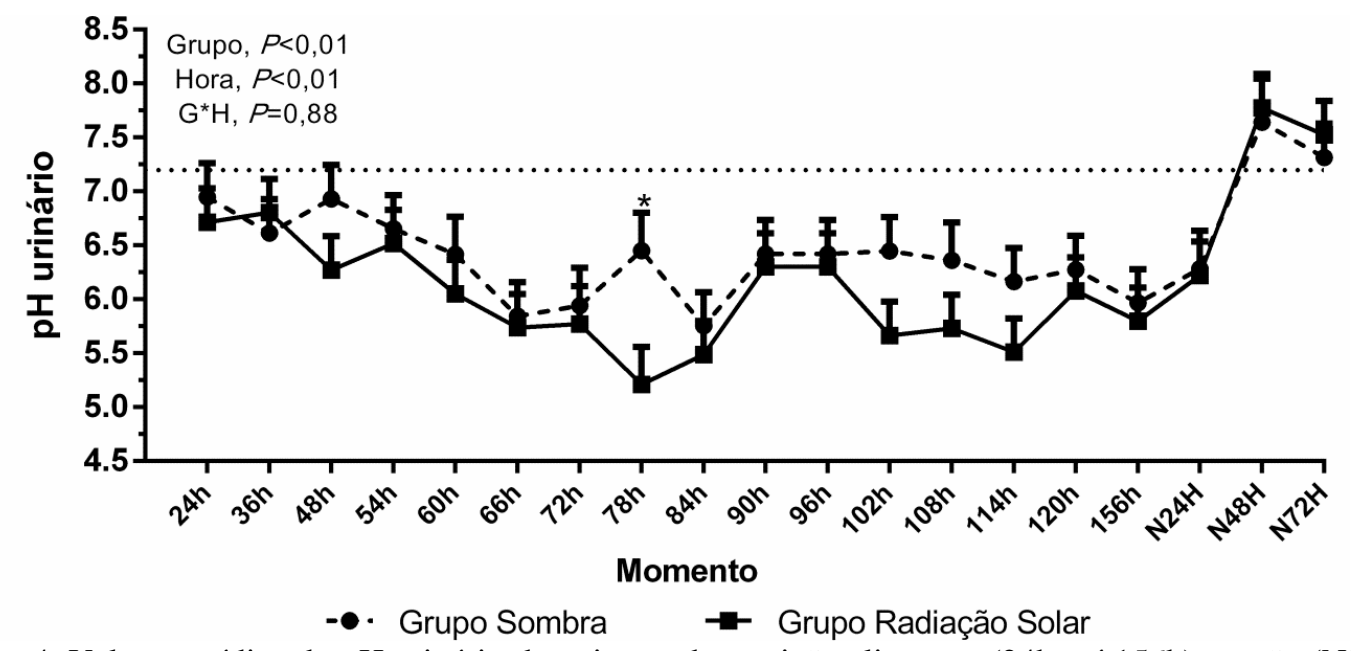

Figura 4. Valores médios do pH urinário de ovinos sob restrição alimentar (24h até 156h) ou não (N24h; N72h), expostos à radiação solar ou à sombra, no município de Capão do Leão, Rio Grande do Sul, Brasil. Linha pontilhada indica limite inferior de referência para o parâmetro dessa espécie (Navarre e Pugh, 2002). *Diferença significativa $(\mathrm{P}<0,05)$ entre os grupos pelo teste de Tukey. N24H: $24 \mathrm{~h}$ após o início do período de fornecimento da dieta. N48H: 48 h após o início do período de fornecimento da dieta. N72H: 72h após o início do período de fornecimento da dieta.

Em geral, o GS teve consumo numericamente maior, $0,808 \mathrm{~kg} / \mathrm{dia}$, quando comparado ao GRS, $0,774 \mathrm{~kg} / \mathrm{dia}$, detendo um acréscimo de $5 \%$ a mais durante o período. Entretanto, com relação a essa variável, a única diferença constatada foi no dia 2 (Fig. 3), em que a média do GRS foi menor que a do GS $(\mathrm{P}<0,05)$, coincidindo também com a maior média de TR encontrada no GRS. A partir daí, pode-se inferir que, nesse dia, a capacidade de dissipação de calor desses animais não foi eficiente, o que, consequentemente, aumentou a condição de estresse térmico e afetou a ingestão de alimentos.

As condições de estresse calórico provocam queda no consumo de matéria seca de até $55 \%$ na tentativa de minimizar a produção de calor e aumento de 7 a $25 \%$ das exigências de mantença animal (Nutrient..., 2001). Devem-se considerar as mudanças comportamentais, como procura por sombra e aumento da ingestão de água (não mensurados no estudo) e da ofegação, como concorrência com a ingestão, pois a maior ingestão de água inibe o apetite e a ofegação impede a ingestão de alimentos (Dalcin, 2013). Ainda, o estresse provocado por calor atua no hipotálamo estimulando a saciedade e inibindo a fome, reduzindo, assim, o consumo dos alimentos (West, 2003).

A ingestão voluntária de MS é muito afetada pela temperatura ambiente e diminui a partir de $25^{\circ} \mathrm{C}$ a $27^{\circ} \mathrm{C}$ de temperatura média diária (Beede e Collier, 1986). Condições ambientais, como temperatura do ambiente e umidade relativa do ar, estão inter-relacionadas e seus efeitos combinados devem ser considerados quando se determina a influência do estresse térmico sobre a ingestão de alimentos. Dessa forma, o índice de temperatura e umidade (ITU) pode descrever mais adequadamente a sensação térmica que incide sobre os animais. Alguns estudos relataram reduções na ingestão diária de MS quando o ITU mínimo excede 57 e continua até atingir 72 (Holter et al., 1996; Ravagnolo et al., 2000). Na maioria dos momentos avaliados no estudo aqui descrito, as temperaturas e os dados de ITU se mantiveram altos, porém não foi possível inferir que esses fatores tenham sido determinantes para alterar o comportamento de ingesta de alimentos. 


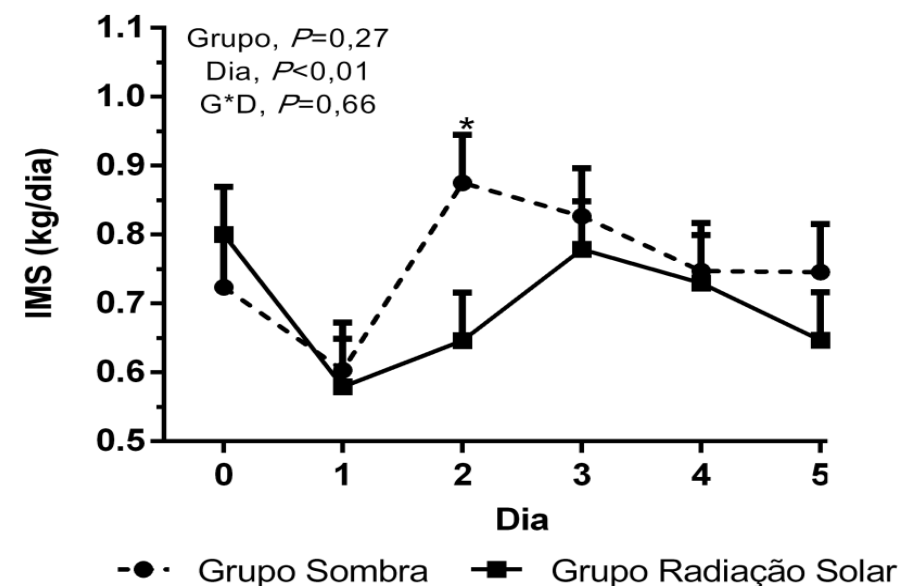

Figura 3. Ingestão de matéria seca média [IMS $(\mathrm{kg} / \mathrm{dia})]$ de ovinos expostos à radiação solar ou à sombra durante seis dias, sem restrição alimentar, no período experimental, no município de Capão do Leão, Rio Grande do Sul, Brasil. *Diferença significativa $(\mathrm{P}<0,05)$ entre os grupos pelo teste de Tukey.

Diversos são os fatores estressantes que acometem ovinos nos diferentes sistemas de criação e regiões pelo território brasileiro influenciando, em muitos casos, a capacidade adaptativa e produtiva desses animais. A metodologia aqui utilizada teve como objetivo recriar cenários possíveis de serem encontrados em países de clima tropical e subtropical com condições climáticas adversas (altas temperaturas) e períodos de escassez de alimentos, fazendo com que os resultados encontrados possam ser extrapolados para as diferentes realidades vivenciadas a campo por muitos ovinocultores.

Assim, torna-se cada vez mais importante avaliar a forma com que os animais existentes em rebanhos do Brasil respondem fisiologicamente a esses fatores estressantes e quais as possíveis alternativas que visem minimizar os efeitos destes efeitos, promovendo bem-estar e potencializando a produtividade.

\section{CONCLUSÃO}

Ovelhas que sofrem restrição alimentar durante períodos de alta temperatura e umidade têm menor frequência respiratória e temperatura interna, independentemente de estar na sombra ou pleno sol. Porém, quando normalizado a oferta de alimento as ovelhas em pleno sol têm menor ingestão de matéria seca.

\section{REFERÊNCIAS}

AGRICULTURE engineering technology guide. Iowa: LPHSI, 1990.

AQUINO R.S.; LEMOS, C.G.; ALENCAR, C.A. et al. A realidade da caprinocultura e ovinocultura no semiárido brasileiro: um retrato do sertão do Araripe, Pernambuco. PUBVET, v.10, p.271-355, 2016.

BARBOSA, O.R.; SILVA, R.G. Índice de conforto térmico para ovinos. Bol. Ind. Anim., v.52, p.29-35, 1995.

BEEDE, D.K.; COLLIER, R.J. Potencial nutritional strategies for intensively managed cattle during thermal stress. J. Dairy Sci., v.62, p.543-555, 1986.

CASELLA, S.; GIUDICE, E.; PASSANTINO, A. et al. Shearing induces secondary biomarkers responses of thermal stress in sheep. Anim. Sci. Papers Rep., v.34, p.73-80, 2016.

DALCIN, V.C. Parâmetros fisiológicos em bovinos leiteiros submetidos ao estresse térmico. 2013. 49f. Dissertação (Mestrado em Zootecnia Produção Animal) - Faculdade de Agronomia, Universidade Federal do Rio Grande do Sul, Porto Alegre, RS.

FEITOSA, F.L.F. Exame físico geral ou de rotina. In: FEITOSA, F.L.F. Semiologia veterinária-a arte do diagnóstico. 3.ed. São Paulo: Roca, 2014. p.51-67. 
FREITAS, A.C.B.; QUIRINO, C.R.; BASTOS, R. Bem-estar de ovinos: Revisão. PUBVET, v.11, p.18-29, 2017.

FURTADO D.A.; CARVALHO JR, S.S.; LOPES NETO, J.P. et al. Adaptability of sheep to three salinity levels in different environments. Semin. Ciênc. Agrár., v.41, p.283-292, 2020.

HABIBU, B.; DZENDAJ, T.; AYOL, O.; YAQUBM, S.; KAWU, U. Haematological changes and plasma fluid dynamics in livestock during thermal stress, and response to mitigative measures. Livest. Sci., v.214, p.189-201, 2018.

HOLTER, J.B.; WEST, J.W.; McGILLIARD, M.L.; PELL, A.N. Predicting ad libitum dry matter intake and yields of Jersey cows. J. Dairy Sci., v.79, p.912-921, 1996.

LAEGER, T.; METGES, C.C.; KUHLA, B. Research review: role of $\beta$-hydroxybutyric acid in the central regulation of energy balance. Appetite, v.54, p.450-455, 2010.

MARAI, I.F.M.; EL-DARAWANY, A.A.; FADIEL, A.; ABDEL-HAFEZ, M.A.M. Physiological traits as affected by heat stress in sheep - a review. Small Ruminant Res., v.71, p.112, 2007.

NAVARRE, C.B.; PUGH, D.G: Pregnancy toxemia. In: PUGH, D.G. Sheep and goat medicine. Philadelphia: Saunders, 2002.

NEFF, R.A.; EDWARDS, D.; PALMER, A. et al. Reducing meat consumption in the USA: a nationally representative survey of attitudes and behaviours. Public Health Nutr., v.21, p.18351844, 2018.

NUTRIENT requirements of dairy cattle. Washington, D.C.: National Academy of Sciences, 2001. 363p.

RAVAGNOLO, O.; MISZTAL, I.; HOOGENBOOM, G. Genetic component of heat stress in dairy cattle, development of heat index function. J. Dairy Sci., v.83, p.2120-2125, 2000.

RIBEIRO, L.A.O. et al. Perfil metabólico de borregas Corriedale em pastagem nativa do Rio Grande do Sul. Acta Sci. Vet., v.31, p.167-170, 2003.
RICCI, G.D.; TITTO, C.G.; SOUZA, R.T. Enriquecimento ambiental e bem-estar na produção animal. Rev. Ciênc. Agrovet., v.16, p.324-331, 2017.

SEJIAN, V.; MAURYA, V.P.; KUMAR, K.; NAQVI, S.M.K. Effect of multiple stresses on growth and adaptive capability of Malpura ewes under semi-arid tropical environment. Trop. Anim. Health Prod., v.45, p.107-116, 2012.

SEJIAN, V.; MAURYA, V.P.; NAQVI, S.M.K. Adaptive capability as indicated by endocrine and biochemical responses of Malpura ewes subjected to combined stresses (thermal and nutritional) in a semi-arid tropical environment. Int. J. Biometeorol., v.54, p.653-661, 2010.

SILANIKOVE, N. Effects of heat stress on the welfare of extensively managed domestic ruminants. Livest. Prod. Sci., v.67, p.1-18, 2000.

SILVA N.V.; COSTA, R.G.; FREITAS, C.R.G. et al. Alimentação de ovinos em regiões semiáridas do Brasil. Acta Vet. Bras., v.4, p.233-241, 2010

SILVA R.G.; STARLING, J.M.C. Evaporação cutânea e respiratória em ovinos sob altas temperaturas ambientes. Rev. Bras. Zootec., v.32, p.1956-1961, 2003.

SOUSA JUNIOR, S.C.; MORAIS, F.; EVANGELISTA, D.A. et al. Características termorreguladoras de caprinos, ovinos e bovinos em diferentes épocas do ano em região semi-árida. Rev. Cient. Prod. Anim., v.10, p.127-137, 2008.

TAFFAREL, L.E.; COSTA, P.B.; POZZA, M.S.S. et al. Correlação entre características físicas, $\mathrm{pH}$ e contagem bacteriana da urina de ovinos. Synergismus Scyent., v.7, n.1, 2012.

VIANA, J.G.A. Panorama geral da ovinocultura no mundo e no Brasil. Rev. Ovinos, v.4, p.44-47, 2008.

WEST, J.W. Effects of heat-stress on production in dairy cattle. J. Dairy Sci., v.86, n.6, p.21312144, 2003. 